\title{
A TEACHERS' PERCEPTION OF LITERACY STRATEGIES APPLIED IN EDUCATIONAL ACTIVITIES
}

\author{
Nicoleta MESEȘAN, Ph.D, Candidate, \\ A Doctoral School „Educational, Reflection, Development”, Babes-Bolyai University, \\ Cluj-Napoca, Romania \\ nicoletamese@yahoo.com
}

\begin{abstract}
The article highlights the perspective of high-school teachers working in a pedagogical profile regarding the application of literacy strategies in various disciplines and the importance of such strategies in the development of functional literacy in students. The method used for this study has been investigation, and the tool used to collect information has been the survey. The data has been analyzed using SPSS software, version 22.0. The elements examined through pilot study returned a reliability rate in between 0.62 and 0.822 . Results have shown that teachers can partially define literacy, but they do not frequently apply, in their teaching activity, strategies that would develop students' abilities. This study is paramount in the context of the PISA exams taken by students in Romania, which revealed the scale of functional illiteracy in pupils. Furthermore, the relevance of the study resides in the analysis of teachers' perception of literacy strategies from the perspective of forming students as functional literate adults, but also as future teachers for primary school.
\end{abstract}

Keywords: literacy; functional literacy; literacy strategies;

\section{Introduction}

In the always expanding and dynamic current society, the young generation must be trained to adapt quickly to change and successfully deal with the novelties that occur in all areas of the social and professional life. In this way, the school and, implicitly, the teachers have a special mission: to help the students develop the learning abilities that will support their effective adjustment to change, but, at the same time, to make maximum use of their creative potential.

Literacy is both a path and a purpose in reaching these objectives: when it's learned as an ability for study, literacy becomes a working instrument for the entire life.

\subsection{Literacy - conceptual delimitations}

What is literacy? This new concept for the lexicon of the Romanian language is used in many educational systems. Literacy is defined by the OCDE (The Organization for Economic Cooperation and Development) as "the aptitude to understand and use written information in daily life, at home, at work in a group, so that the person in question may reach certain personal purposes and develop their knowledge and faculties." (OCDE, 2000). In the OCDE document - Glossary of Statistical Terms (2003), literacy is defined as "the ability to understand, use and reflect on written texts in order to reach one's objectives, to develop one's knowledge and potential and participate effectively in society" (https://stats.oecd.org/glossary/detail). The term literacy is translated in Romanian as alphabetisation, meaning learning to read and write. In order to distinguish between basic alphabetisation and functional alphabetisation, we will continue to use the term literacy. 


\subsection{Functional illiteracy in Romania}

Literacy can be analyzed from the point of view of functional alphabetisation, a complex term which defines the ability of an individual to use written information in daily activities. In order to reach this level, forming literacy abilities during mandatory schooling is essential. In the Romanian educational system there is a major deficit in forming these abilities in students. A large number of students that take the PISA exams show a low level in their abilities for learning and analysis of the given text and in the usage of the learned information in new contexts. The official document published by the Ministry of Education presents the general results of the Romanian students in the PISA exams: „35\% of the Romanian students are on the level 2. Below level 2, meaning levels 1a, $1 \mathrm{~b}$ and below $1 \mathrm{~b}$ are $38,6 \%$ of the students. Cummulatively, on the higher levels $-3,4$ and $5-$ are $27,5 \%$ of the Romanian students.” (https://www.edu.ro/rezultatele-elevilor-rom\%C3\%A2ni-la-testareaoecd-pisa-2015). Level 2 is considered to be the basic level that must be reached at the end of the mandatory studies so that a 15 years old youngster may continue his studies effectively or to be integrated on the labor market. As the data presented above indicates, $35 \%$ of the Romanian students are on the basic level and nearly 39\% are below this basic level. These students are not illiterate, they know how to read and write, maybe they even memorised a lot of information. The students' illiteracy is functional, meaning they don't understand what they read and don't know how to apply the learned information. This is a great alarm signal for the current educational system.

\subsection{The literacy-functional illiteracy relationship}

The literacy strategies applied in the didactic activity aim to form literacy abilities in students. After these abilities are developed, the students can use these strategies in the learning activity in all of the fields of study. "As the students make progress in school, they are asked to read more and more complex information. The ability to understand and use information from these texts is essential for the student's success in the learning process (Think literacy - Introduction to Reading to Strategies http://www.edu.gov.on.ca/eng/studentsuccess/thinkliteracy/files/reading.pdf).

In order for students to be successful in learning they must master a diverse repertoire of strategies and learn how to use them when selecting information and apply them in various circumstances. The literacy strategies ,use a variety of graphical characteristics and text in order to organize the main ideas, to ilustrate key-concepts and emphasize important details and helpful information. These features will help the reader to select information and make connections. The readers who understand how to use these strategies need less time to decipher the text", as it is mentioned in Reading Strategies - Introduction to Reading Strategies (http://www.edu.gov.on.ca/eng/studentsuccess/thinkliteracy/files/reading.pdf ).

It's important for students to link information, because they give meaning to learning by interconnecting notions and, thus, a holistic informational system is formed. In this way, the fundamentals for an applicative, effective learning are constituted. If the teacher uses literacy strategies in various disciplines, the students will develop their own study system which will become a basic tool in the permanent education, in forming the learning to learn competence.

\section{The methodology of research}

The study uses inquiry as a method of research and the tool is the survey. The survey is made up of 5 questions, some with multiple choice, others with an open answer, so the respondants have the possibility to express their point of view regarding the importance and usage of literacy strategies in teaching thier own discipline. The survey was applied to a group of 50 teachers of different specialties who teach in pedagogical vocational high-schools 
in Romania. The teachers were selected from pedagogical high-schools because the graduates of these high-schools will become teachers in primary schools and pre-schools, so the literacy strategies used in the teaching-learning activity will be a support for students in forming functional literacy, but also a model for the future career in teaching. The results were interpreted by using the SPSS software, version 22.0. The elements that were studied through pilot study have shown a reliability between 0.62 and 0.822 .

\section{The results and interpretation of the research}

The interpretation of the results has pointed out different perspectives of the teachers on the literacy strategies. The quantitative analysis of the results indicate a few educational realities.

Most of the teachers who were questioned state that they are familiarized with the notion of literacy $(50 \%, 25$ teachers), but $50 \%$ are in the category of those who are not familiarized or don't know whether this notion is familiar to them or not.

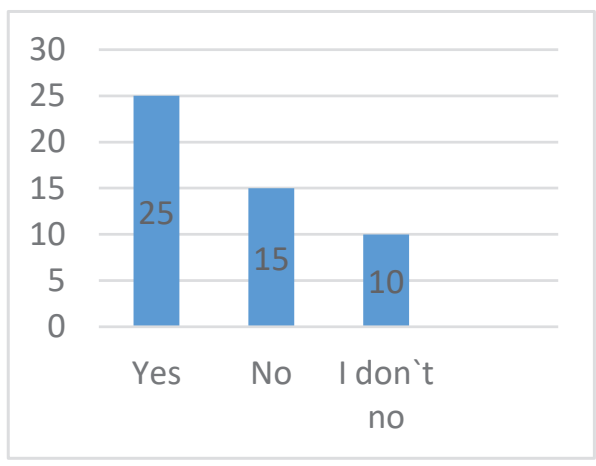

Fig. 1. You are familiarized with the notion of literacy strategies

Literacy was defined as the study of the written text by $40 \%$ (20 subjects) of the people who were wuestioned, the study of text with the purpose of learning it 20\% (10 subjects) of the respondents and reflecting on what was read (16\%, 8 subjects). It's interesting that $4 \%$ (2) of the respondents have defined literacy as an operation which enables decoding and recomposing the text in order to realize the didatic transposition so that the text might become accessible to the students, therefore a wrong interpretation of the term. Other answers were: the ability to decode and apply information from a text that was read so that the message would be clearly received and processed (10\%, 5 subjects), understanding the text (4\%, 2 subjects) and the emission of valuable judgment on the text (4\%, 2 subjects).

In the didactic activity, 16 of the teachers that were questioned (32\%) have followed the steps of a literacy strategy, but most of them answered with no or I don't know. Some teachers explained their choice of the negative answer: the discipline that was taught (n.a. Maths) doesn't require such strategies!

The pozitive aspects that can be noticed in the didactic activities were literacy strategies have been used are: the students acquire the new knowledge consciously, according to their own possibilities (15\%), efficient solving of the tasks related to the given text $(25 \%$, 25 subjects). Most of the teachers' answer should also be noticed: the students become more calm. Other answers were: (13\%) capturing interest for books, stating some personal opinions on a given subject, assimilating the message of the text and connecting information with other information that was already assimilated.

When forming the didactic competence in students from pedagogical schools, the literacy strategies are considered important by $28 \%$ (14) teachers who were questioned, $63,3 \%$ (30) don't know, and 6,3\% don't believe that literacy strategies are important. We will 
now mention a few of the srguments that support the importance of the strategies: they develop empathy, educate patience, develop communication, the speciality language is formed, (the students) learn how to learn. We will now mention a few of the arguments of the negative answers: the presentation and exemplification of a didactic method is much easily understood than if it's studied in theory, the students learn better through exemplification or the teacher's model.

After analyzing the answers given by the teachers, a superficial knowledge of the terms literacy and literacy strategies can be noticed. This stems from the eronous definition of the concept. Some subjects claim that they are familiar with these notions, but they only offer partial definitions or partially correct definitions, and out of the 50 subjects, over $50 \%$ (25) don't know or don't even know if they have information on these notions. The application of literacy strategies in the didactic activity was done by 16 subjects $(32 \%)$, some of whom have argued that these strategies are not suitable for the discipline that theya re teaching. But it is known that literacy implies the receival, analysis and interpretation of a written message in any field: literature, Maths, Physics etc. There are different literacy strategies for different fields that help the students select information from various texts and link the information with another that is already known to them.

The teachers who applied literacy strategies in didactic activity have signaled serious difficulties that can be easily correlated with the functional illiteracy of students: the indolecnce of students who are not willing to reflect or make an effort, insufficient patience to read, a low ability of students to select information, formulate main ideas or extract the keynotions from a text.

The answer to the question Do you consider the literacy strategies useful in the formation of the didactic competence in students (the teacher-educator speciality)? is surprising. Only 28\% (14) consider these strategies to be important, and 70\% don't consider them useful or don't know. As it can be noticed from the answers, the profesional competence of the teacher is reduced to their abilities, while knowledge and the attitudes are ignored.

Even though only some subjects agree that literacy strategies have a major contribution in forming the didactic competence in students, it should be noticed that positive aspects that are extremely valuable about the use of literacy strategies in the didactic activity are mentioned, such as: the students understand much better if they read and explain a text in their own words; the students acquire new knowledge consciously, according to their own possibilities; the particular message of the text is easily assimilated by the students and they manage to make connections that they will be able to use later; organized learning that can be measured immediately.

\section{Conclusions}

After this survey, we can draw the following conclusions:

Most of the teachers-subjects in the current research are in the beginning of the methodical information and formation in the field of literacy;

A reticent attitude of the subjects when using literacy strategies in the didactic field can be noticed. This aspect can be detrimental to the students who will become, in turn, teachers in primary school and pre-school;

The results of the study, even if they can't be ignored in the entire body of teachers from our country, reflects a reality that can explain the functional illiteracy of the students;

The study can be expanded on a representative sample in order to obtain a whole picture of application and awareness of the importance of the literacy strategies in the didactic activity. 
The literacy strategies are a valuable way of helping the students acquire abilities of study and become functionally literate adults. Literacy is ,a key-ability, but also a keymeasure of the education of the people" (Roser, Ortiz-Ospina, 2018), and the duty of forming this ability belongs to the teachers.

\section{References:}

Max Roser and Esteban Ortiz-Ospina (2018) - Literacy. Published online at

OurWorldInData.org. retrieved from: https://ourworldindata.org/literacy

Shanahan C., Shanahan, T. (2018)Teaching Disciplinary Literacy. University of Ilinois at Chicago

retrieved from https://shanahanonliteracy.com/publications/disciplinary-literacy-montana

Glossary of Statistical Terms(2003), OECD

retrieved from https://stats.oecd.org/glossary/detail

Reading Strategies. Introduction to Reading Strategies

retrieved from http://www.edu.gov.on.ca/eng/studentsuccess/thinkliteracy/files/reading.pdf

Think literacy- Introduction to Reading to Strategies.

retrieved from http://www.edu.gov.on.ca/eng/studentsuccess/thinkliteracy/files/reading.pdf

http://www.edu.gov.on.ca/eng/studentsuccess/thinkliteracy/files/reading.pdf

https://www.edu.ro/rezultatele-elevilor-rom\%C3\%A2ni-la-testarea-oecd-pisa-2015

\section{Appendices:}

A suervey destined for the teachers in order to analyze the perception on the literacy strategies:

1. Circle the chosen answer:

Are you familiar with the notion of literacy strategies?

1.Yes 2. No 3. I don't know

1. What do you understand through literacy?

2. Circle the chosen answer:

When teaching, did you follow the steps of a literacy strategy?

1. Yes 2. No 3. I don't know

3. Describe, in short, the difficulties that you encountered in class when you applied literacy strategies.

4. Mention the positive aspects that you noticed during the activities that were based on literacy strategies.

5. Do you consider literacy strategies useful in forming the didactic competence in students?

1. Yes 2. No 3. I don't know

6. Note at least two arguments for the previous answer. 